\title{
Simulation of the Low-Emissive Coatings Influence on Double-Glazed Windows Thermal Parameters.
}

\author{
Vasilyev G.P. ${ }^{\text {a, } 1}$, Lichman V.A. ${ }^{\text {b, } 1}$, Peskov N.V. ${ }^{\text {c, } 1}$, Yurchenko I.A. ${ }^{\text {d, } 1}$ \\ ${ }^{1}$ JSC "INSOLAR-INVEST", Moscow, Russia
}

\begin{abstract}
This paper presents a one-dimensional dynamical model, based on the heat balance equations and calculations of thermal parameters for triple-glazed windows with various low-emissive coatings. The described study was performed with the financial support of the Ministry of Education and Science of Russia.Contract ID RFMEFI57614X0034.
\end{abstract}

\section{Introduction.}

Thermal properties of window units have increased dramatically lately. Nowadays methods of mathematical simulation are a vital part of study and prediction of thermal properties of translucent constructions [16]. Reduction of heat transfer by radiation is one of the most effective ways to increase thermal resistance of a triple-glazed window unit. The ability of glass to reflect long-wave radiation is determined by its transmissibility, which usually equals 0.84 . The less its absolute value is, the more heat will be reflected back into the room. Glass, being a dielectric, possesses transmissibility value bigger than metals, which is one of the reasons for radiation heat loss. To reduce transmissibility, the glass surface is coated with heat-reflective low-emissive coatings, which allows the visible light to pass, yet reflects almost all thermal energy in long-wave IR. This paper presents onedimensional mathematical model, based on the heat balance equations, perpendicular to the surface that allows studying thermal properties of triple-glazed windows with different low-emissive coatings.

\section{Description of mathematical model.}

Figure 1 shows the structure and essential parameters of the model: three glass panes, having thickness of $d_{g}$, thermal conductivity coefficient of $\lambda_{g}$, divided by air cavities having width of $d_{a}$ and thermal conductivity coefficient $\lambda_{a}, T_{-}$and $T_{+}$- are external and internal air temperatures. Heat transfer with convection occurs on external and internal window surfaces, having coefficients of $\alpha_{-}$and $\alpha_{+}$respectively.

Heat radiation occurs on glass surfaces facing the air cavities. Heat flow from a surface area unit is calculated according to Stefan's law $Q=\varepsilon \sigma T^{4}$, where coefficient showing emissive ability related to black body emissive ability, Stefan-Boltzmann constant, T absolute temperature of the surface.

The heat balance equation for such a system is a nonlinear thermal conductivity equation

$$
\frac{d}{d x}\left(\lambda \frac{d T}{d x}\right)+F(x ; T)=0
$$

with boundary conditions

$$
\left.\frac{d T}{d x}\right|_{-}=\alpha_{-}\left(T_{-}-T\right),\left.\quad \frac{d T}{d x}\right|_{+}=\alpha_{+}\left(T_{+}-T\right)
$$

The F function equals zero, except on glass surfaces emitting or absorbing heat.

It should be mentioned that the model does not take into account the emission external surfaces of the window block, facing outside and inside the building. It is assumed to be compensated by ambient heat absorption.

\footnotetext{
$\overline{\mathrm{d}}$ Corresponding author: iyurchenko@insolar.ru

aPVassiliev@mail.ru;

bvalitsch@mail.ru;

peskovnick@gmail.com
} 
The method of finite differences is used for the numerical solution of the boundary value problem. Differential problem is replaced by a system of finite differences equations at discrete points $\mathrm{xi}=\mathrm{ih}, \mathrm{i}=1,2 \ldots$ $\mathrm{N}$, having temperature $\mathrm{Ti}$ :

$\frac{1}{h}\left(\alpha_{-}\left(T_{-}-T_{1}\right)-\frac{\lambda_{g}}{h}\left(T_{1}-T_{2}\right)\right)=0 \quad$ external window boundary;

$\frac{1}{h}\left(\frac{\lambda_{g}}{h}\left(T_{i-1}-T_{i}\right)-\frac{\lambda_{g}}{h}\left(T_{i}-T_{i+1}\right)\right) \quad$ internal points of the glass;

$\frac{1}{h}\left(\frac{\lambda_{a}}{h}\left(T_{i-1}-T_{i}\right)-\frac{\lambda_{a}}{h}\left(T_{i}-T_{i+1}\right)\right)$ internal points of the cavity;

$\frac{1}{h}\left(\frac{\lambda_{g}}{h}\left(T_{N_{1}-1}-T_{N_{1}}\right)-\frac{\lambda_{a}}{h}\left(T_{N_{1}}-T_{N_{1}+1}\right)-E_{1}\right)$

glass-air border, 1st cavity;

$\frac{1}{h}\left(\frac{\lambda_{a}}{h}\left(T_{N_{2}-1}-T_{N_{2}}\right)-\frac{\lambda_{g}}{h}\left(T_{N_{2}}-T_{N_{2}+1}\right)+E_{1}\right) \quad$ airglass border, 1st cavity;

$\frac{1}{h}\left(\frac{\lambda_{g}}{h}\left(T_{N_{3}-1}-T_{N_{3}}\right)-\frac{\lambda_{a}}{h}\left(T_{N_{3}}-T_{N_{3}+1}\right)-E_{2}\right)$,

glass-air border, 2nd cavity;

$\frac{1}{h}\left(\frac{\lambda_{a}}{h}\left(T_{N_{4}-1}-T_{N_{4}}\right)-\frac{\lambda_{g}}{h}\left(T_{N_{4}}-T_{N_{4}+1}\right)+E_{2}\right)$

air-glass border, 2nd cavity;

$\frac{1}{h}\left(\frac{\lambda_{g}}{h}\left(T_{N-1}-T_{N}\right)-\alpha_{+}\left(T_{N}-T_{+}\right)\right)=0 \quad$ internal

window boundary;

, where $E_{1}=\frac{\varepsilon_{12} \varepsilon_{21}}{\varepsilon_{12}+\varepsilon_{21}-\varepsilon_{12} \varepsilon_{21}}\left[\left(T_{N_{1}}\right)^{4}-\left(T_{N_{2}}\right)^{4}\right]$;

$E_{2}=\frac{\varepsilon_{22} \varepsilon_{31}}{\varepsilon_{22}+\varepsilon_{31}-\varepsilon_{22} \varepsilon_{31}}\left[\left(T_{N_{3}}\right)^{4}-\left(T_{N_{4}}\right)^{4}\right]$.

The non-linear system of finite differences equations is solved using Newton's method with initial approximation, equal to the temperature distribution in the model, calculated without the radiation, having $\mathrm{ij}=$ 0 .

Thermal resistance of the window without the heat radiation is calculated according to the formula:

$$
R=\frac{T_{+}-T_{-}}{\alpha_{-}\left(T_{1}-T_{-}\right)}
$$

\section{Results of calculation.}

Design inside temperature is $\mathrm{T}+=20{ }^{0} \mathrm{C}$, design outside temperature is $\mathrm{T}-=-28{ }^{0} \mathrm{C}$ (winter conditions), $\mathrm{T}-=+35$ ${ }^{0} \mathrm{C}$ (summer conditions), glass thermal conductivity coefficient is $\lambda \mathrm{g}=0.76 \mathrm{Bm} /(\mathcal{M} \cdot K)$, air cavity thermal conductivity is $\lambda_{a}=0,035 \cdot B m /(\mathcal{M} \cdot K)$, heat transfer coefficients are respectively $\alpha_{-}=23$ $B m /\left(M^{2} \cdot K\right), \alpha_{+}=8 B m /\left(M^{2} \cdot K\right)$, glass pane thickness is $\mathrm{dg}=4 \mathrm{~mm}$, air cavity width is da $=16 \mathrm{~mm}$. Emission coefficients of other panes eij have constant value of 0,84

Figure 1-2 show the results of calculations for the winter conditions. It is obvious that thermal resistance of a triple-glazed window decreases as the emission coefficient grows. When emission coefficient reaches the value of $\varepsilon=0.84$ low-emissive coatings seize to increase thermal resistance of a triple-glazed window.

When low-emissive coatings are applied to two glass surfaces, maximum thermal resistance is achieved when coatings are made on inner surfaces of the first and the third glass panes $R_{12-31}$. The same effect may be achieved by coating surfaces in different air cavities of a triple-glazed window. $R_{12-31}=R_{12-22}=R_{21-22}=R_{21-31} \quad$. Thus, when emission coefficient is $\varepsilon=0.02$ thermal resistance of the triple-glazed window is $R_{12-31}=1.08 \cdot \mathcal{M}^{2} \cdot \mathrm{K} / \mathrm{Bm}$, and when emission coefficient is $\varepsilon=0.84$, thermal resistance of the triple-glazed window is $R_{12-31}=0.57 \cdot \mathrm{M}^{2} \cdot \mathrm{K} / \mathrm{Bm}$, almost twice as much and $\Delta R_{12-31} / R_{12-31}=(1.08-0.57) / 0.57=0.9$

Temperature distribution in both triple-glazed windows is the same.

When low-emissive coatings is applied to two surfaces in the same cavity, thermal resistance of the triple-glazed window will decrease: $R_{22-31}=0.81 \cdot \mathrm{M}^{2} \cdot \mathrm{K} / \mathrm{Bm}$, $R_{12-21}=0.79 \cdot \mathrm{M}^{2} \cdot \mathrm{K} / \mathrm{Bm}$ for emission coefficient $\varepsilon=0.1$, thus $R_{12-31}>R_{22-31}>R_{12-21}$. Therefore, to maximize thermal resistance of the triple-glazed window low-emissive coatings, having lowest possible emission coefficients should be applied to glass surfaces in different cavities.

Figure 2 shows the temperature distribution in both tripleglazed windows. When two low-emissive coatings are applied to the surfaces in the first cavity $(12-21)$, the temperature of the middle glass pane is higher, and when they are applied to the surfaces in the second cavity $(22-31)$ - lower, the temperature of the middle glass pane, when the low-emissive coatings are applied to the surfaces in different cavities. At the same time, the temperature of the third glass pane, the one facing inside 
the building, is several degrees lower, when low-emissive

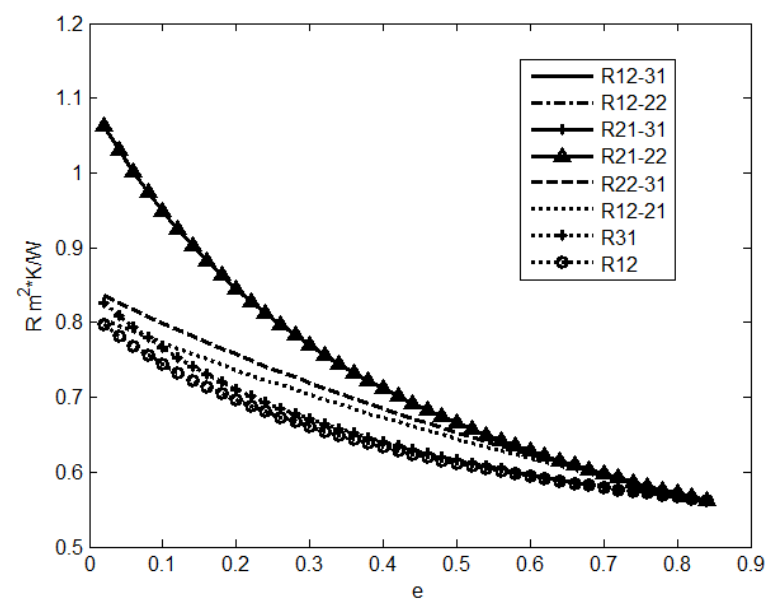

Figure.1. - Relationship between thermal resistance and emission coefficient for a triple-glazed window, having external air temperature of $T_{-}=-28^{0} \mathrm{C}$ and different methods of applying low-emissive coatings.

When low-emissive coatings are applied to the external glass panes, the temperature on the middle one is several degrees higher in winter and several degrees lower in summer. This ensures more comfortable conditions inside the building. Usually, to prevent the middle glass pane from overheating in summer ("thermal shock" effect), applying low-emissive coatings to inner surfaces of external glass panes is recommended.

If low-emissive coating is applied only to one glass surface of a triple-glazed window, its thermal resistance will be lower, and $R_{12-31}>R_{31}=R_{22}>R_{12}=R_{21}$. Thus, at emission coefficient of $\varepsilon=0.1$, thermal resistance of a triple-glazed window is: $R_{12-31}=0.98 \cdot \mathrm{M}^{2} \cdot \mathrm{K} / \mathrm{Bm}$

$R_{31}=0.77 \cdot \mathcal{M}^{2} \cdot \mathrm{K} / \mathrm{Bm}$ and

$R_{12}=0.75 \cdot \mathrm{M}^{2} \cdot \mathrm{K} / \mathrm{Bm}$

Thermal resistance of the triple-glazed window decreases as the thermal conductivity coefficient of the air cavity is increased. When thermal conductivity coefficient is $\lambda_{a}=0,07 \cdot \mathrm{Bm} /(\mathcal{M} \cdot \mathrm{K})$ and emission coefficient is $\varepsilon=0.02$, thermal resistance of the tripleglazed window is $R_{12-31}=0.63 \cdot \mathrm{M}^{2} \cdot \mathrm{K} / \mathrm{Bm}$, but when emission coefficient is $\varepsilon=0.84$, $R_{12-31}=0.45 \cdot \mathrm{M}^{2} \cdot \mathrm{K} / \mathrm{Bm}$

$\Delta R_{12-31} / R_{12-31}=(0.63-0.45) / 0.45=0.4$ cavities of the triple-glazed windows with lowemissive coatings should be filled with inert gases. It decreases thermal conductivity coefficient and increases thermal resistance of a triple-glazed window. Besides, if cavities are filled with inert gases, they can show the same width, while maintaining the same thermal coatings are applied in the same cavity.

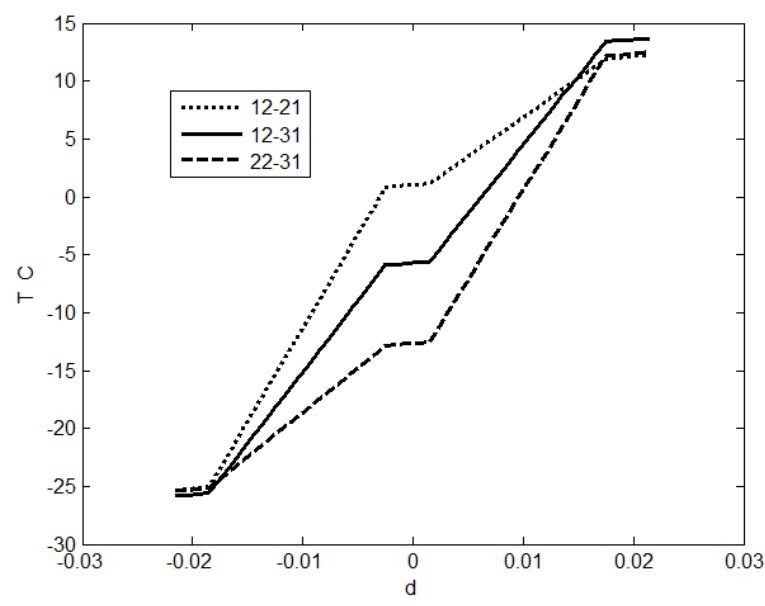

Figure.2. - Temperature distribution inside the tripleglazed window, with design external temperature

$T_{-}=-28^{0} \mathrm{C}$

and different ways of applying low-emissive coatings on the glass panes.

resistance, thus reducing heat loss caused by "thermal bridges" effect.

\section{Conclusions.}

From results of calculations can make next conclusion:

The following may be concluded from the calculation results:

- to maximize thermal resistance of the triple-glazed window low-emissive coatings, having lowest possible emission coefficients should be applied to glass surfaces in different chambers: $R_{12-31}=R_{12-22}=R_{21-22}=R_{21-31}$;

- Thermal resistance of a triple-glazed window with one low-emissive glass, will be lower than the same window with two low-emissive glasses, and $R_{12-31}>R_{22-31}>R_{12-21}>R_{31}=R_{22}>R_{12}=R_{21}$;

- simultaneous implementation of low-emissive coatings and inert gases filling the cavities ensure considerable increment of thermal resistance of the tripleglazed window.

Acknowledgements: This paper contains the results of research performed with financial support from the Ministry of Education and Science of the Russian Federation contract ID RFMEFI57614X0034.

\section{References.}

1. ISO 15099 Thermal Performance of Windows, Doors and Shading Devices - Detail Calculation

2. EN 673 Glass in building - Determination of thermal transmittance (U value) - Calculation method

3. ISO 10211:2007 Thermal bridges in building construction - Heat flows and surface temperatures Detailed calculations

4. Gustavsen, A., Kohler, C., Arasteh, D., and Dalehaug, A. Two-dimensional computational fluid dynamics 
and conduction simulations of heat transfer in horizontal window frames with internal cavities, ASHRAE Transactions, 2007, 113(1), 165-175

5. Lichman V.A., Dubinsky S.I. Heat flow distribution inside the windows // Transparent constructions (Свентопрозрачные конструкции), 2009, №5-6, $76-81$

6. Lichman V.A., Peskov N.V. Calculation of humidity distribution insede the window unit using the finate elements method, Roofing and insulating materials (Кровельные и изоляционные материалы), № 4, 2010,35-37 